\title{
Fatal Covid-19 in a Malnourished Child with Megaloblastic Anemia
}

\author{
Rajesh K. Kulkarni ${ }^{1}$ (D) Aarti A. Kinikar ${ }^{1} \cdot$ Tushar Jadhav $^{1}$
}

Received: 12 May 2020 / Accepted: 10 June 2020/Published online: 17 June 2020

(C) Dr. K C Chaudhuri Foundation 2020

To the Editor: Children with COVID-19 have relatively mild presentation and less mortality [1]. Malnourished children have sarcopenia and higher risk of death due to infections [2]. We report a case of fatal COVID-19 disease in a severely malnourished young child.

A 13-mo-old girl presented with fever for $2 \mathrm{~d}$, vomiting, refusal to feed and breathlessness for one day prior to admission with increasing paleness and lethargy since two weeks. There was no history of cough or runny nose, contact with a COVID positive case or premorbid significant illness. History of faulty complementary feeding was noted with calorie and protein deficient diet.

On examination, child had severe pallor with $2 \mathrm{~cm}$ palpable liver (span $6 \mathrm{~cm}$ ) and no splenomegaly. Child had severe acute malnutrition (length $62 \mathrm{~cm}$, weight $5.9 \mathrm{~kg}$, weight for length below $-3 \mathrm{SD}$ and mid upper arm circumference $11.5 \mathrm{~cm}$ ) with hyperpigmentation of hands and feet indicating B12 deficiency. Tachypnea (respiratory rate $44 / \mathrm{min}$ ) and tachycardia (heart rate $140 / \mathrm{min}$ ) were noted. Blood pressure was $76 / 40 \mathrm{mmHg}$ (5th to 50th centile). Chest examination revealed no adventitious sounds. $\mathrm{SpO}_{2}$ in air was $96 \%$.

Initial laboratory workup revealed hemoglobin of $2.2 \mathrm{~g} / \mathrm{dl}$, total white cell count of 13,000/cumm (Neutrophil: Lymphocyte ratio, NLR 0.28) and platelet count of 105,000/ cumm. Peripheral smear showed macrocytes and hypersegmented neutrophils. Serum bilirubin was $2.1 \mathrm{mg} / \mathrm{dl}$ (indirect $1.7 \mathrm{mg} / \mathrm{dl}$ ) with normal transaminases and deranged PT INR (2.1). Blood and urine cultures were sterile. Chest Xray showed mild right parahilar infiltrates.

A swab for SARS CoV2 was positive by RT-PCR. There was significantly elevated serum ferritin $(1976 \mathrm{ng} / \mathrm{ml})$, CRP $(2.8 \mathrm{mg} / \mathrm{dl})$, D-dimer levels $(8.5 \mathrm{mg} / \mathrm{L})$ and serum triglycerides $(270 \mathrm{mg} / \mathrm{dl})$. Vitamin B12 levels were low $(50 \mathrm{ng} / \mathrm{ml})$.

Rajesh K. Kulkarni

docrajesh75@yahoo.com

1 Department of Pediatrics, B. J. Government Medical College, Pune, Maharashtra, India
A possibility of infection induced Hemophagocytic lymphohistiocytosis (HLH) was thought (in view of persistent fever, pancytopenia, hyperferritenemia, hypertriglyceridemia and hemophagocytosis on bone marrow), child was given IV methylprednisolone and IVIG apart from meropenem and B12. However, the child developed progressive anemia, leukopenia and thrombocytopenia. In view of worsening respiratory distress with hypoxia and chest X-ray showing acute respiratory distress syndrome (ARDS), the child was mechanically ventilated and standard ARDS management was followed. However, child succumbed to COVID-19 on day 6 of admission. Bone marrow confirmed Hemophagocytic lymphohistiocytosis.

Malnutrition affects both the innate and adaptive immune responses [3] with longer viral persistence and increased trafficking of inflammatory cells to lungs. Insufficient protein intakes may lead to nutrition-related sarcopenia [4]. Some micronutrients including B12 have important role in innate immune responses [5].

To the best of our knowledge, this is the first case report of a severely malnourished child with severe megaloblastic anemia and HLH succumbing to COVID-19. It may be worthwhile exploring if malnutrition and vitamin B12 deficiency are independent risk factors for severe COVID-19 disease.

\section{Compliance with Ethical Standards}

Conflict of Interest None.

\section{References}

1. Wang $\mathrm{D}, \mathrm{Hu} \mathrm{B}, \mathrm{Hu} \mathrm{C}$, et al. Clinical characteristics of 138 hospitalized patients with 2019 novel coronavirus infected pneumonia in Wuhan, China. JAMA. 2020;323:1061-9.

2. Bhutta ZA, Berkley JA, Bandsma RHJ, Kerac M, Trehan I, Briend A. Severe childhood malnutrition. Nat Rev Dis Primers. 2017;3: 17067. 
3. Alwarawrah Y, Kiernan K, MacIver NJ. Changes in nutritional status impact immune cell metabolism and function. Front Immunol. 2018;9:1055.

4. Gerriets VA, MacIver NJ. Role of T cells in malnutrition and obesity. Front Immunol. 2014;5:379.
5. Taylor AK, Cao W, Vora KP, et al. Protein energy malnutrition decreases immunity and increases susceptibility to influenza infection in mice. J Infect Dis. 2013;207:501-10.

Publisher's Note Springer Nature remains neutral with regard to jurisdictional claims in published maps and institutional affiliations. 